\title{
PORTFOLIO SELECTION OF INFORMATION SYSTEMS PROJECTS USING PROMETHEE V WITH C-OPTIMAL CONCEPT
}

\author{
Jonatas A. de Almeida*, Adiel T. de Almeida and Ana Paula C.S. Costa \\ Received April 25, 2012 / Accepted June 12, 2013
}

\begin{abstract}
This paper presents a multicriteria decision model for selecting a portfolio of information system (IS) projects, which integrates strategic and organizational view within a multicriteria decision structure. The PROMETHEE V method, based on outranking relations is applied, considering the $c$-optimal concept in order to overcome some scaling problems found in the classical PROMETHEE V approach. Then, a procedure is proposed in order to make a final analysis of the $c$-optimal portfolios found as a result of using PROMETHEE V. Also, the organizational view is discussed, including some factors that may influence decision making on IS projects to be included in the portfolio, such as adding the company's strategic vision and technical aspects that demonstrate how IS contributes value to a company's business.
\end{abstract}

Keywords: multiple criteria analysis, PROMETHEE V, $c$-optimal portfolio concept, project portfolio, information system planning, information technology priorities.

\section{INTRODUCTION}

One of the most difficulties issues when selecting information system (IS) or information technology (IT) projects is to evaluate benefits. Using a limited vision of financial gains can have a serious adverse effect on this analysis. Besides the difficulty of measurement, amongst the main aims of an IS project, there are aims other than financial issues. For instance, to be considered satisfactory, a project should support objectives in the strategic vision of the organization (Doherty et al., 1999; Min et al., 1999; Hackney \& Little, 1999).

To make sure that the ISs selected support strategic objectives, the planning of ISs should be aligned with the strategic planning of the organization. Besides the strategic criteria, other criteria have a strong influence on the ISs selection. Jiang and Klein (1999) were among the first to address the strategic issue related to selecting an information system portfolio, by regarding this as a problem that evolves various stages, including the evaluation and selection of alternatives. These characteristics make it more difficult to make decisions on allocating resources in the IS environment.

*Corresponding author

Federal University of Pernambuco, Cx. Postal 7462, 50630-970 Recife, PE, Brazil.

E-mails: jonatasaa@yahoo.com.br; almeidaatd@gmail.com; apcabral@hotmail.com 
This paper deals with the IS selection problem by using an organizational planning methodology that is attached to the PROMETHEE V method. This multicriteria method works with outranking relations for selecting a portfolio of IS projects. In order to overcome some scaling problems found in PROMETHEE V, the $c$-optimal concept is applied, by means of using a proposed procedure which makes a final analysis of the $c$-optimal portfolios found.

Also, this paper discusses the importance of the process of selecting ISs integrated with a methodology of planning information systems. Although a few studies may be found in the literature that deal with the selection of Information Systems as a multi-criteria decision problem (Jiang \& Klein, 1999; Zopounidis, 1999; Bernroider \& Stix, 2006), most of them make the selection dissociated from the context of Information Systems Planning. A numerical application illustrates the use of the model proposed, which is based on an application in a computer science company.

\section{MULTICRITERIA MODEL FOR SELECTION OF IS}

\subsection{Previous work related to IS project selection}

Profit in the short term is an objective common to organizations, when they analyze their portfolio of IS projects. On the other hand, an approach, that aligns evaluating ISs projects to the organization's strategy, facilitates the measurement of the benefits from investments in ISs (Teo et al., 1996; Teo \& King, 1997; Doherty et al., 1999; Henderson \& Venkatraman, 1999; Teo \& Ang, 1999; Bergeron et al., 2004).

Taking this into account some studies have given different results for the efficiency of IS investments. According to Zopounidis (1999), the financial analysis should be inserted into a general context, and thus be one of the criteria considered in decision making, so that the relative importance of each criterion can be considered.

The traditional approaches to making a financial assessment of investments seek to satisfy only the management's objectives. Milis \& Mercken (2004) state that an IS investment project is usually a group decision, and each decision maker (DM) has a group of criteria, which each DM evaluates in line with the importance he/she gives it. It is desirable to have the cooperation of these decision makers, which can be reached by incorporating the critical factors that may affect them into the decision making process.

Angelou \& Economides (2008) proposed a multicriteria model based on the Analytic Hierarchy Process (AHP) method so as to prioritize information and communication technology projects. Chen \& Cheng (2009) assert that this uncertainty involves business goals, benefits, project risks and limited available resources, and they proposed a multicriteria model based on fuzzy measurement and the fuzzy integral. Each IS project has different benefits that have to be considered in the selection process. According to Mehrez et al. (1993), Zopounidis (1999) and Lee \& Kim (2000), this characteristic associated with the cost of each project and the budget available to select them makes selecting an IS project a multicriteria portfolio selection problem.

It seems more appropriate to adopt a multicriteria methodology that works with the portfolio problematic to support IS investments, considering that its characteristics is very much associated with the various levels of the organization and the criteria involved. Schniederjans \& Santhanam 
(1993) discuss the importance of tackling IS project selection as a portfolio selection problem instead of one that prioritizes IS projects. Klapka \& Pinos (2002) proposed a method to consider this interdependence amongst IS projects with a portfolio selection approach using an additive multicriteria decision model that considers the synergy amongst projects in the value function of the portfolio and in the constraints equations when appears mutually exclusive IS projects appear. Also, Schniederjans \& Santhanam (1993) demonstrated an application of a multicriteria portfolio approach and a multicriteria ranking approach, comparing both results and showed that the portfolio approach reaches a better global result.

\subsection{Multicriteria Model for Selecting IS Integrated with an Organization's Processes}

Among the methodologies of IS planning presented in the literature, this paper concentrates on the methodology called Business System Planning (Almeida et al., 1992). In this methodology, setting out from the Strategic Vision of the organization, Information System Modules (ISMs) are determined which are structured out of a matrix segmentation of two viewpoints in order that information can be brought together, namely the Cluster of Information Systems (CIS) and an Information System Functional Approach (IFA). In a version adapted from BSP methodology (Almeida et al., 1992, 1999; Almeida \& Costa, 2002), under the first viewpoint (CIS), pieces of information are clustered together in accordance with their nature. More specifically, an attempt is made to segment the information related to processes which also take into account classes of data. In the case of IFA, what is used, basically, is the paradigm proposed by Sprague and Watson (1989) and IFA takes into consideration the three basic approaches to information systems, viz., Transactional Information Systems (TIS), Management Information Systems (MIS) and Decision support systems (DSS) in addition to which there are: Executive Information Systems (EIS) and Automation of Production Systems (APS).

Modularization, then, consists of cross-matching each CIS with each of the IFAs, thus obtaining the Information System Modules (ISMs). These can be visualized by means of a matrix, in which each column is associated with a CIS and each row, with an IFA. Thus the resulting cells correspond to the ISMs.

The literature provides the evidence to show that for an organization to take the correct decision on the investment in ISs, what is of fundamental importance is integration between the organization's strategic vision and the planning of ISs in the most complete manner possible (Pollalis, 2003; Kearns \& Lederer, 2004).

In addition to needing to transfer the business strategy to IS applications, organizations are faced with the problem of, after having identified the most appropriate ISs and constructed the portfolio of IS projects, having to define the order of implementation of these projects in view of the limitation on resources, which, in effect, represents the investment decision in ISs. Nevertheless, this scenario with its rapid and frequent changes increases the risks of investments in ISs going wrong. It is a fact that the changes in the environment usually imply changes in the direction of the business, and this can result in alterations to IS projects which were initially selected as having priority, thus compromising or making the investment decision unviable. Due to these variations, the processes of selecting ISs and how to decide on investment are extremely important stages in the planning process and in the case of BSP methodology no formal procedure is defined to support the prioritization stage of Information System Planning. 
As mentioned previously, the BSP methodology allows, based on the company's strategic vision, Information Systems Projects or ISMs to be compiled, but it does not provide a formal procedure to select from among these ISMs the one(s) that will be implemented. As per the literature (Jiang \& Klein, 1999; Zopounidis, 1999; Bernroider \& Stix, 2006), the ISMs selecting process should be addressed as a multicriteria decision problem. Hence, in order to make it possible to apply a multicriteria approach in compiling the BSP, so as to select ISMs, a model is put forward for obtaining the evaluation of each ISM in the light of each criterion defined for the selection processes. All ISM selection processes should be conducted by an information analyst who should interview the decision-maker to identify his/her preference for results from the ISM selection processes. The decision-maker is a business manager.

The process of selecting ISMs is based on classifying modules by means of identifying the decision-maker's intensity of preference for one ISM rather than another, based on his/her judgment in relation to criteria, principally including the vision of the organizational processes, directly associated with the Strategic Management of the Organization.

The result of applying the decision model to the selection is directly obtained from the structure of the ISMs. At a preliminary selection stage, evaluations should be obtained for the ISMs, for each criterion. As seen in a matrix, $m$ CISs and $r$ IFAs are considered, corresponding to a total of $z$ ISMs, such that $z=m . r$.

In order to structure the selection model which incorporates the PROMETHEE V method, basically three pieces of information will be obtained from the decision-maker.

The decision-maker establishes the relative weights for the criteria, and the general criterion to establish his/her intensity of preference between the alternatives for each criterion. The decisionmaker further establishes the parameters associated with each general criterion: the limit of preference (p) and the limit of indifference (q). The general criteria, the weights of the associated criteria and parameters, are items of information obtained directly from the decision-maker. The evaluation of each alternative for each criterion, within the context of the information systems Planning methodology used, has to be obtained from the structure as set out in the following items.

This information will be obtained through evaluating each ISM as a function of each criterion $c$, in the form of the matrix $\left\|m_{i j}\right\|$, shown below. Each cell represents one ISM, by means of a combination of CISs (columns) and IFAs (rows).

$$
\left\|m_{i j}\right\|=\left[\begin{array}{cccc}
m_{11} & m_{12} & \ldots & m_{1 c} \\
m_{21} & & & \\
\ldots & & & \\
m_{z 1} & \ldots & \ldots & m_{z c}
\end{array}\right] \text {, such that } z=m \cdot r .
$$

The Model consists of obtaining an ISM matrix for each criterion. This Matrix is re-organized and presented in the form suitable for evaluation by the PROMETHEE V method. 
Thus, evaluations will be obtained of the ISMs for each criterion, which will be represented by matrices in the following form, considering $c$ criteria, $m$ CISs and $r$ IFAs:

$$
\left\|m_{i j}^{c}\right\|=\left[\begin{array}{cccc}
m_{11}^{c} & m_{12}^{c} & \ldots & m_{1 m}^{c} \\
m_{21}^{c} & & & \\
\ldots & & & \\
m_{r 1}^{c} & \ldots & \ldots & m_{r m}^{c}
\end{array}\right] .
$$

Using the Information System Planning methodology, three sets of criteria will be obtained:

- Strategic criteria

- Criteria of processes, and

- Technical criteria

The strategic criteria are obtained via strategic Planning, at a higher hierarchical level. The criteria for processes are obtained by evaluations of the processes, at a hierarchical level below the strategic criteria. The technical criteria are also at a lower level of the hierarchy, related to the types of information service used.

What follows shows how three groups of criteria are obtained in the form of matrices $\left\|m_{i j}^{c}\right\|$.

The strategic criteria are the criteria identified in the first stage of the methodology for Information System Planning. The evaluation of the CISs from the perspective of these criteria is obtained as shown below.

By analyzing the degree of adherence of $p$ processes to $\mathrm{n}$ strategic criteria, a definition is made of the matrix below which establishes a relation between the strategic criteria and the processes, such that $\sum_{i=1}^{p} r_{i j}=1$; for any $j$, and $0 \leq r_{i j} \leq 1$. The closer to 1 the $r_{i j}$ the greater is the adherence degree of the process to the strategic criterion.

$$
\left\|r_{i j}\right\|=\left[\begin{array}{cccc}
r_{11} & r_{12} & \ldots & r_{1 n} \\
r_{21} & & & \\
\ldots & & & \\
r_{p 1} & \ldots & \ldots & r_{p n}
\end{array}\right] .
$$

Now what is obtained is the degree of relationship of the CISs with the p processes, defined by the matrix below, which is obtained based on the technical analysis in the Information Engineering stage:

$$
\left\|r a_{i j}\right\|=\left[\begin{array}{cccc}
r a_{11} & r a_{12} & \ldots & r a_{1 p} \\
r a_{21} & & & \\
\ldots & & & \\
r a_{m 1} & \ldots & \ldots & r a_{m p}
\end{array}\right]
$$


in such a way that $0 \leq r a_{i j} \leq 1$; and $\sum_{i=1}^{m} r a_{i j}=1$, for any $j$. The closer to 1 the $r a_{i j}$, the greater is the relationship degree of the CIS with the process.

After having established the ratios of processes v strategic criteria and CISs v processes, we shall transfer the evaluations of the processes in relation to the strategic criteria for the CISs, thus obtaining the evaluation of the CISs in the light of the strategic criteria.

The matrix below establishes the evaluation of the CISs based on each strategic criterion, this being obtained as follows:

$$
\begin{aligned}
& \left\|s g_{i j}\right\|=\left[\begin{array}{cccc}
s g_{11} & s g_{12} & \ldots & s g_{1 n} \\
s g_{21} & & \\
\ldots & & & \\
s g_{m 1} & \ldots & \ldots & s g_{m n}
\end{array}\right] \\
& \left\|s g_{i j}\right\|=\left\|r a_{i k}\right\| \cdot\left\|r_{i j}\right\|=\left\|\sum_{k=1}^{p} r a_{i k} r_{k j}\right\|,
\end{aligned}
$$

where: $0 \leq s g_{i j} \leq 1$; and $\sum_{i=1}^{m} s g_{i j}=1$, for any $j$.

Nevertheless, what we wish is to obtain not only the evaluation of the CISs for the strategic criteria, but the evaluation of the ISMs. As an ISM is the combination of CIS and IFA, we need to obtain the matrix which represents the degrees of participation of the IFAs in each CIS. The matrix below represents this participation, considering $\sum_{i=1}^{r} t a_{i j}=1$ for any $j$, and $0 \leq t a_{i j} \leq 1$ :

$$
\left\|t a_{i j}\right\|=\left[\begin{array}{cccc}
t a_{11} & t a_{12} & \ldots & t a_{1 m} \\
t a_{21} & & & \\
\ldots & & & \\
t a_{r 1} & \ldots & \ldots & t a_{r m}
\end{array}\right] .
$$

In order to obtain the matrix mcij which supplies the evaluation of the ISMs for the strategic criterion $c$, the above matrix is used. The matrices $\left\|m_{i j}^{c}\right\|$, relative to the strategic criteria, are obtained for each criterion $c$. Each matrix is obtained through the following relation:

$$
m_{i j}^{c}=t a_{i j} \cdot g_{j}^{c} \text {, for any } i \text { and } j
$$

In which, the vectors $g_{j}^{c}$, for each criterion $c$, are defined, which correspond to the vectors which supply the evaluation of the CISs for each criterion $c$. The vector $g_{j}^{c}$ corresponds to column $c$ of the matrix $s g_{i j}$, such that $g_{j}^{c}=s g_{i c}$, for any $i$ and $j$.

Equally, the set of matrices $\left\|m_{i j}^{c}\right\|$ for the criteria of processes must be obtained, for as previously mentioned, these criteria differ only from the strategic criteria on account of their nature and hierarchical level. 
For each process criterion $c$, there will be a vector $p_{j}^{c}$, with the evaluation of the processes in accordance with the criterion $c$.

Using the matrix raij, described in the previous item, we transfer the evaluations of the processes, from the perspective of the criteria for processes to the CISs.

Thus the vector $g_{j}^{c}$ is obtained as follows:

$$
\left\|g_{j}^{c}\right\|=\left\|r a_{i j}\right\|\left\|p_{j}^{c}\right\|
$$

Similarly, $\left\|m_{i j}^{c}\right\|$ is obtained by applying (2) to the criteria for processes.

Thereafter, the set of matrices $\left\|m_{i j}^{c}\right\|$ for the technical criteria should be obtained.

The technical criteria take the IFAs into consideration in a different way from the strategic criteria and from those for processes which take the CISs into consideration.

For each technical criterion $c$, there will be a vector $t_{i}^{c}$, with the evaluation of the IFAs in accordance with the criterion $c$. It is observed that this evaluation is undertaken by a specialist in information systems, at the Information Engineering stage.

Finally, $\left\|m_{i j}^{c}\right\|$ for the technical criteria are obtained through the following relation:

$$
m_{i j}^{c}=a t_{i j} \cdot t_{i}^{c}, \text { for any } i \text { and } j
$$

$a t_{i j}$ is the matrix, see below, which presents the degrees to which the CISs use each IFA, considering $\sum_{j=1}^{m} a t_{i j}=1$ for any $i$, and $0 \leq a t_{i j} \leq 1$ :

$$
\left\|a t_{i j}\right\|=\left[\begin{array}{cccc}
a t_{11} & a t_{12} & \ldots & a t_{1 m} \\
a t_{21} & & & \\
\ldots & & & \\
a t_{r 1} & \ldots & \ldots & a t_{r m}
\end{array}\right] .
$$

The relative weight of all the criteria is represented by the vector $\left\|c_{i}\right\|$, considering a total of $d$ criteria, such that $\sum_{i=1}^{d} c_{i}=1$ and $0 \leq c_{i} \leq 1$.

Included among the $\mathrm{d}$ criteria are the $\mathrm{n}$ strategic criteria, the weights of which are represented by the vector $\left\|e_{i}\right\|$, which are evaluated directly by the decision-maker. Thus, the first $\mathrm{n}$ elements of the vector $\left\|c_{i}\right\|$ correspond to the strategic criteria and are obtained from the vector $\left\|e_{i}\right\|$, the $d-n$ final elements of the vector $\left\|c_{i}\right\|$ also being directly evaluated by the decision-maker. The decision-maker will still have to establish a weighting factor $(w f)$ for the group of strategic criteria in comparison with the importance of the set of process and technical criteria, such that $0 \leq w f \leq 1$.

The final weight of the strategic criteria in the vector $\left\|c_{i}\right\|$, corresponding to the first $\mathrm{n}$ elements, will be given by: $c_{i}=w f \cdot e_{i}$ for $0 \leq i \leq n$. 
In order to incorporate the results obtained above in the form suitable for evaluation by the PROMETHEE II method, what will be used are the vector $\left\|c_{i}\right\|$ and the matrix $\left\|m_{i j}\right\|$, which represents the evaluation of all the $z$ ISMs by all the criteria.

It should be observed that the columns of the matrix $\left\|m_{i j}\right\|$ represent the evaluation of the set of ISMs for each criterion. The rows show the ISMs, by means of a combination of CISs and IFAs. $\left\|m_{i j}\right\|$ is obtained from the set of matrices $\left\|m_{i j}^{c}\right\|$. Thus, columns $c$ of $\left\|m_{i j}\right\|$ are obtained by means of the matrices $\left\|m_{i j}^{c}\right\|$. That is, the values of the column mij correspond to the values of the matrix $\left\|m_{i j}^{1}\right\|$, in which the elements are renumbered in ranking $r$ of classification by column and then by row.

Using matrix $\left\|m_{i j}\right\|$ and vector $\left\|c_{i}\right\|$, and having defined the general criteria for each criterion, what is obtained, for each criterion, is a matrix with the degree of outranking $\pi(a, b)$ for each pair of alternatives $(a, b)$, and based on the matrices obtained, the indices $\phi^{+}(a)$ and $\phi^{-}(a)$ are calculated, thus establishing the ISM classification process by the PROMETHEE V method.

\section{MULTICRITERIA SELECTION OF IS PORTFOLIO}

This section presents an overview on previous work found on literature related to multicriteria portfolio. A focus is give to non-compensatory approach to multicriteria portfolio selection, showing the way to outranking methods and then considering the PROMETHEE V method. This leads to use of $c$-optimal portfolio concept in PROMETHEE V. Then, a procedure is proposed in order to implement this $c$-optimal portfolio concept, which is appropriate for an outranking method.

\subsection{Previous work related to multicriteria portfolio}

There are several multicriteria decision aid methods, which may be used for different kinds of decision problems or a distinct problematic. The PROMETHEE (Preference Ranking Method for Enrichment Evaluation) method, used in this paper, consists of constructing, a relation of outranking values (Brans et al., 1984; Brans \& Vincke, 1985). This is a method applied in a vast range of multicriteria problems (Behzadian et al., 2010).

The literature on multicriteria portfolio problems presents several different approaches to deal with portfolio when multiple criteria have also to be combined. Salo et al. (2011) present a broad view on this subject, although most of the work is concentrated in the multicriteria compensatory rationality for portfolio. Argyris et al. (2011) presents a new model for Portfolio MC applying Knapsack Problem to additive multicriteria function, defining the decision maker preferences through a limitation of space of weights. Kleinmuntz (2007) uses portfolio Decision Analysis for resource allocation decision problem in planning healthcare provision. Liesiö et al. (2008) presents a model for project portfolio selection with a multi-objective binary linear programming problems in situations in which are interdependencies between projects and the information is incomplete about the cost and the budget. Mild \& Salo (2009) uses a multiattribute value function combined with an optimization model for prioritizing maintenance funds for public infrastructure. 
The work conducted by Kiesling et al. (2011) considers visualization methods for multicriteria portfolio selection that may be useful for future work on the kind of problem approached here, as discussed latter.

Clemen \& Smith (2007) deals with baseline issue related to additive models, which are specifically related to multicriteria compensatory rationality for portfolio. Although this paper is related to a non-compensatory rationality, using an outranking problem, it is interesting point out the problem described by Clemen \& Smith (2007). The baseline problem described in Clemen $\&$ Smith (2007) deals with a problem of baseline for multicriteria additive model, which uses an interval scale for the individual projects evaluation. In our paper we deal with an outranking approach, which uses the ratio scale for projects scores, which is rather different from the additive model case. In their case, of additive model, the zero of the scale means the worst performance in a given criterion (not performance zero). Therefore, when a project is not included in the portfolio, receiving value $=0$, then, it is implicitly assumed that this results in the worst performance for all criteria.

On the other hand, the outranking method builds their scores for alternatives based on summation of weights, which is based on a ratio scale. That is, it does not compute the performance of outcomes of alternatives by criteria. Instead of that, this performance is applied to compare which alternative has a greater value in a pair-wise process. As it is usual in MCDM methods, the weights are obtained in a ratio scale. In this case, the zero means the absence of that property, while in the interval scale, for instance, the zero means a minimum value. An alternative with zero score in PROMETEE means that its outflow (positive flow) does have the same value as the inflow (negative flow), which is computed in equation (5). The outflow is a measure related to the degree of outranking over all other alternatives and the inflow is a measure related to the degree in which this alternative is outranked by all other alternatives.

Since, the focus of this study is related to non-compensatory rationality for multicriteria portfolio selection, the following section considers the PROMETHEE V method, which leads to the $c$-optimal portfolio concept.

\section{2 c-optimal portfolio concept for PROMETHEE V}

For each criterion, the decision-maker must establish a weight $p_{j}$ which increases with the importance of the criterion for the DM. PROMETHEE can use six different ways to define how the decision-maker may represent his preferences, not necessarily using the same form for all the criteria. They are general criteria, used to indicate the intensity of the preference (Brans \& Vincke, 1985). PROMETHEE V is based on PROMETHEE II. In the PROMETHEE II method, the net flow of alternative $\mathrm{i}$ is obtained as follows:

$$
\phi_{i}=\phi_{i}^{+}-\phi_{i}^{-}
$$

where:

$\phi_{i}^{+}$is the outflow of alternative $i$, and

$\phi_{i}^{-}$is the inflow of alternative $i$. 
The solution for PROMETHEE V (Brans \& Mareschal, 1992) is obtained as follows:

$$
\begin{aligned}
\operatorname{Max} & \sum_{i=1}^{n} \phi_{i} x_{i} \\
\text { subject to } & \sum_{j=1}^{r} b_{j} x_{j} \leq B,
\end{aligned}
$$

where:

$x_{i}$ is a binary variable, indicating whether the project related to ISM $i$ is included in the portfolio. $b_{i}$ is the cost of the project related to ISM $i$.

$B$ is the available budget, which is the constraint for implementing the projects.

There is an important issue related to the scores of alternatives. Some alternatives have positive scores (net flows) and others have negative scores. Mavrotas et al. (2006) mention that this issue was not clarified in previous studies on PROMETHEE V, since all the signs of the net flow should be positive in the objective function in (6). They suggest transforming all the net flows from PROMETHEE II into non-negative scores by changing the scaling of the net flows, with the following transformation: $\phi_{i}^{\prime}=\phi_{i}+\left|\min _{i}\left(\phi_{i}\right)\right|$. Where, $\min _{i}\left(\phi_{i}\right)$ is the minimum net flow (which is negative) considering all the alternatives.

However, a problem with this scaling transformation can be seen. First, the alternative with the minimum net flow would never be considered for the portfolio, since its net flow would be nil. This may suggest that the problem would be overcome, by adding an additional value, let us say $\varepsilon$, as follows:

$$
\phi_{i}^{\prime}=\phi_{i}+\left|\min _{i}\left(\phi_{i}\right)\right|+\varepsilon
$$

Let $k>\left|\min _{i}\left(\phi_{i}\right)\right|$ and the following transformation could be applied:

$$
\phi_{i}^{\prime}=\phi_{i}+k
$$

However, Almeida \& Vetschera (2012) have shown that this is not enough, since the scaling change with (7) may also lead to recommending different portfolios. They have shown that different results may be obtained from (7). That is, one can obtain different recommendation for portfolios depending on the value of the constant $k$. As shown by Almeida \& Vetschera (2012) while linear transformations in the scaling of the net flows do not change the results for PROMETHEE II, they may change the results for portfolios in PROMETHEE V. This kind of transformation works adequately for evaluating the alternatives in PROMETHEE II, although it does not work for evaluating portfolios, where the value of the portfolio $(\mathrm{P})$ depends on the number of alternatives in the portfolio. 
To overcome this scaling problem we use the $c$-optimum concept for PROMETHEE V proposed by Vetschera and Almeida (2012). The $c$-optimum PROMETHEE V consists of solving the following model:

$$
\begin{array}{cl}
\text { Max } & \sum_{i=1}^{z} \phi_{i} x_{i} \\
\text { subject to } & \sum_{i=1}^{z} b_{i} x_{i} \leq B \\
& \sum_{i=1}^{z} x_{i}=c .
\end{array}
$$

The model (8) consists of selecting the best portfolio with a number of $c$ projects. Almeida \& Vetschera (2012) have proved that the $c$-optimal portfolio for a given value of $c$ remains the same for any value of the transformation parameter $k$ for the formulation of the model (8).

Comparison among these $c$-optimal portfolios has been pointed out by Almeida \& Vetschera (2012) as a further issue to be considered. Therefore, we present in this paper a procedure in order to implement the $c$-optimal concept in PROMETHE V, which is subsequently applied to the IS portfolio selection.

\subsection{A procedure for implementing the $c$-optimal portfolio concept in PROMETHEE V}

Although Almeida \& Vetschera (2012) has suggested the use of the concept of $c$-optimal portfolio, with regard to a procedure for its implementation, they have indicated as a further issue to be worked out. Therefore, a procedure is following proposed in order to make the comparison among these $c$-optimal portfolios, which will allow the implementation of this concept.

The above formulation assumes that one does not need to consider $c$-optimum portfolios with $c<p$, since these portfolios will not aggregate an overall value greater than the $p$-optimal portfolio (Almeida \& Vetschera, 2012). Thus, they do not need to be considered for analysis. This is one of the reasons why the use of this concept of $c$-optimal portfolio is not cumbersome. Contrary to a first feeling one could take on this regard.

A procedure for comparing these $c$-optimal portfolios should take into account the rationality present in outranking methods, in order to be consistent with the PROMETHEE approach and therefore being appropriate for this application, assuming non-compensatory rationality. The proposition of such a procedure will depend of the number of portfolios to be compared.

The number of portfolios to be analyzed would be less that $z-p$, recalling that $z$ is the maximum number of projects. It can be seen that the number of $c$-optimum portfolios to be compared decreases in probability as this number increases. This can also been seen by simulation. In most cases, the $p$-optimal portfolio is the only feasible $c$-optimal portfolio, although when looking for the best portfolio one should still be concerned with the scaling problem. Thus, there is a reasonable probability that two portfolios will be found while finding three portfolios is less 
likely, but this is still reasonably plausible. That is, for many practical problems the number of portfolios to be compared may not be as huge as one might otherwise suppose.

Based on these considerations, a procedure is proposed for comparing these $c$-optimal portfolios. The idea is to choose the portfolio based on a concordance index of outranking between portfolios.

Let $C(c, p)$ be the concordance index that the $c$-optimal portfolio outranks the $p$-optimal portfolio. The concordance index, $C(c, p)$, is defined as the summation of weights of each criterion for which the summation of value of all alternatives in the $c$-optimal portfolio for this criterion is greater than the summation of value of all the alternatives in the $p$-optimal portfolio.

Let $C(c, p)$ be the value of the $c$-optimal portfolio for criterion $k$, thus:

$$
P_{k}^{c}=\sum_{i=1}^{z} v_{i k} x_{i},
$$

where: $v_{i k}$ is the value of project $i$ for criterion $k$.

Thus, the concordance index that the $c$-optimal portfolio outranks the $p$-optimal portfolio is given by:

$$
C(c, p)=\sum_{P_{k}^{c}>P_{k}^{p}} c_{k},
$$

where:

$P_{k}^{p}$ is the value of the $p$-optimal portfolio for criterion $k$; and $c_{k}$ is he weight of criterion $k$.

Therefore, the procedure consists of choosing the portfolio with the greatest $C(c, p)$, since $C(c, p)>0.5$. If no concordance index is in accordance with the condition $C(c, p)>0.5$, then the portfolio that will be chosen is the $p$-optimal portfolio.

Thus, selecting the IS portfolio using the model from the previous section is obtained by applying the following procedure:

Step 1 - compute PROMETHEE V classical solution given by (6), changing the scale as per Mavrotas et al. (2006). Let $p=$ the number of alternatives (projects) for this solution. Name this solution the $p$-optimal portfolio.

Step 2 - change the scale according to (7) and compute $c$-optimal portfolios by solving the model in (8) for $c=p+1$, and then for increased values of $c(c=p+2, c=p+3, \ldots)$ as long as a feasible solution can be found.

Step 3 - compute the values of the $p$-optimal portfolio and of each $c$-optimal portfolio for each criterion $k$, by applying (9).

Step 4 - compute the concordance index that the $c$-optimal portfolio outranks the $p$-optimal portfolio $-C(c, p)$, by applying (10).

Step 5 - compare each $c$-optimal portfolio with the $p$-optimal portfolio and chose the best one. 
The use of this procedure is illustrated in the numerical application given in the next section. A discussion of the results shows some important issues related to the practical use of this procedure and the $c$-optimal concept.

\section{NUMERICAL APPLICATION}

The following numerical application is based on a real application that was conducted. Although the real data cannot be presented, the context of the problem, most of the characteristics described and the data may be considered realistic, since they are based on this real situation. The company where the study was conducted aggregates its experience in information technology and how it manages its computing data and resources, with the aim of meeting the demands formulated by the Public Administration of the State of Pernambuco. Within the range of Services it renders, it lists itself as being: the provider of a computerized telecommunications network; the provider of access to services and information; and the computing center for Services and information.

\subsection{IS System specification}

Based on the organization's strategic vision and the Critical Factors for Success (CFSs) identified, the decision-maker (DM) set the following strategic criteria together with their relative levels of importance:

a) New technologies - Prospecting new technologies to evaluate the quality of the Services, with a weight of 0.15 ;

b) Opportunity for new business - Identifying opportunities for new business, with a weight of 0.45 ;

c) Quality of service - Maintaining the level of the quality of the Services rendered, with a weight of 0.40 .

As a result of the business analysis, the macro-processes of the organization were obtained. The relation of the processes with the business data resulted in Clusters of Information, presented in Table 1, being emphasized.

Thereafter, a presentation of the evaluation of the macro-processes is obtained from the DM in the light of the strategic criteria. This corresponds to the DM's judgment of values, presented in Table 2. This kind of information has some organizational and technical issues to be considered and usually the DM may be supported by IS/IT analyst.

In the following stage, the DM defined the criteria of the processes as follows:

a) the importance of automating the processes for the organization; and

b) the user's understanding of, cooperation in and commitment to developing a system for automating the processes. 
Table 1 - Clusters of information System (CIS).

\begin{tabular}{|l|l|}
\hline \multicolumn{1}{|c|}{ CIS } & \multicolumn{1}{c|}{ Macro-processes involved } \\
\hline Planning & Strategic planning and management control \\
\hline Personnel & Personnel management \\
\hline Finances & Financial management \\
\hline Services & $\begin{array}{l}\text { Development of systems, } \\
\text { Integration of systems, } \\
\text { Maintenance and support of systems }\end{array}$ \\
\hline Operation & Operation of systems \\
\hline New technologies & $\begin{array}{l}\text { Management of technological } \\
\text { development and of information }\end{array}$ \\
\hline Commercialization & Commercialization \\
\hline
\end{tabular}

Table 2 - Relation of the macro-processes with strategic criteria $\left\|r_{i j}\right\|$.

\begin{tabular}{|c|c|c|c|}
\hline Macro-processes & $\begin{array}{c}\text { New } \\
\text { technologies }\end{array}$ & $\begin{array}{c}\text { New } \\
\text { business }\end{array}$ & $\begin{array}{c}\text { Quality } \\
\text { of service }\end{array}$ \\
\hline $\begin{array}{c}\text { Strategic planning and } \\
\text { management control }\end{array}$ & 0.1 & 0.05 & 0.10 \\
\hline Personnel management & 0.1 & 0.05 & 0.10 \\
\hline Financial management & 0.05 & 0.05 & 0.10 \\
\hline Development of systems & 0.3 & 0.3 & 0.2 \\
\hline Integration and systems & 0.2 & 0.1 & 0.1 \\
\hline $\begin{array}{c}\text { Maintenance and } \\
\text { support of systems }\end{array}$ & 0.1 & 0.2 & 0.05 \\
\hline Operation of systems & 0.05 & 0.1 & 0.05 \\
\hline $\begin{array}{c}\text { Management of technological } \\
\text { development and of information }\end{array}$ & 0.05 & 0.1 & 0.1 \\
\hline Commercialization & 0.05 & 0.05 & 0.2 \\
\hline
\end{tabular}

Thereafter, the evaluation of the macro-processes in the light of the criteria for the processes is obtained from the DM. This expresses the DM's perception, shown in Table 3.

Besides the groupings of items of information, what are used are the types of Information Systems, which are related to the types of tools used for handling information. The Information System Functional Approaches considered in this application are: TIS - Transactional Information Systems; MIS - Management Information Systems; DSS - Decision Support Systems; EIS - Executive Information Systems; APS - Automation of Production Systems.

The combination of the CISs and the IFAs results in the applications which will comprise the IS portfolio, which are the ISMs, presented in Table 4. Depending on the organization context, some IFAs cannot have any application in CIS. In that case for example, it does not make sense for the IFA Automation of Production Systems to be applied to CIS Planning. For this reason there are some blank lines in Table 4. 
Table 3 - Evaluation of the macro-processes in the light of the criteria for processes $p_{j}^{c}$.

\begin{tabular}{|c|c|c|}
\hline Macro-processes & $\begin{array}{c}\text { Importance } \\
\text { of the automation }\end{array}$ & $\begin{array}{c}\text { User's } \\
\text { commitment }\end{array}$ \\
\hline $\begin{array}{c}\text { Strategic planning and } \\
\text { management control }\end{array}$ & 0.1 & 0.05 \\
\hline Personnel management & 0.1 & 0.1 \\
\hline Financial management & 0.1 & 0.1 \\
\hline Development of systems & 0.2 & 0.2 \\
\hline Integration and systems & 00.1 & 0.1 \\
\hline $\begin{array}{c}\text { Maintenance and } \\
\text { support of systems }\end{array}$ & 0.15 & 0.15 \\
\hline Operation of systems & 0.15 & 0.15 \\
\hline $\begin{array}{c}\text { Management of technological } \\
\text { development and of information }\end{array}$ & 0.05 & 0.1 \\
\hline Commercialization & 0.05 & 0.05 \\
\hline
\end{tabular}

Table 4 - ISMs of the computing science incubator company.

\begin{tabular}{|c|c|c|c|c|c|}
\hline CIS IF A & TIS (1) & MIS (2) & DSS (3) & EIS (4) & APS (6) \\
\hline Planning (1) & $\begin{array}{l}\text { Transactional } \\
\text { Information } \\
\text { on Planning }\end{array}$ & $\begin{array}{l}\text { Management } \\
\text { Information } \\
\text { on Planning }\end{array}$ & $\begin{array}{c}\text { Decision } \\
\text { Support } \\
\text { to Planning }\end{array}$ & $\begin{array}{c}\text { Executive } \\
\text { Information } \\
\text { on Planning }\end{array}$ & - \\
\hline Personnel (2) & $\begin{array}{l}\text { Transactional } \\
\text { Information } \\
\text { on Personnel }\end{array}$ & $\begin{array}{l}\text { Management } \\
\text { Information } \\
\text { on Staff }\end{array}$ & $\begin{array}{l}\text { Decision } \\
\text { Support } \\
\text { to Staff }\end{array}$ & - & - \\
\hline Finance (3) & $\begin{array}{l}\text { Transactional } \\
\text { Information } \\
\text { on Finance }\end{array}$ & $\begin{array}{l}\text { Management } \\
\text { Information } \\
\text { on Finance }\end{array}$ & $\begin{array}{l}\text { Decision } \\
\text { Support } \\
\text { to Finance }\end{array}$ & $\begin{array}{l}\text { Executive } \\
\text { Information } \\
\text { on Finance }\end{array}$ & - \\
\hline Services (4) & $\begin{array}{l}\text { Transactional } \\
\text { Information } \\
\text { on Services }\end{array}$ & $\begin{array}{l}\text { Management } \\
\text { Information } \\
\text { on Services }\end{array}$ & $\begin{array}{l}\text { Decision } \\
\text { Support } \\
\text { to Services }\end{array}$ & - & - \\
\hline Operation (5) & $\begin{array}{l}\text { Transactional } \\
\text { Information } \\
\text { on Operation }\end{array}$ & $\begin{array}{l}\text { Management } \\
\text { Information } \\
\text { on Operation }\end{array}$ & $\begin{array}{c}\text { Decision } \\
\text { Support } \\
\text { to Operation }\end{array}$ & - & $\begin{array}{l}\text { Automation } \\
\text { of Production } \\
\text { in Operation }\end{array}$ \\
\hline New Technologies (6) & $\begin{array}{l}\text { Transactional } \\
\text { Information } \\
\text { on NT }\end{array}$ & - & $\begin{array}{l}\text { Decision } \\
\text { Support } \\
\text { to NT }\end{array}$ & $\begin{array}{c}\text { Executive } \\
\text { Information } \\
\text { on NT }\end{array}$ & - \\
\hline Commercialization (7) & $\begin{array}{c}\text { Transactional } \\
\text { Information on } \\
\text { Commercialization }\end{array}$ & $\begin{array}{c}\text { Management } \\
\text { Information on } \\
\text { Commercialization }\end{array}$ & $\begin{array}{c}\text { Decision } \\
\text { Support to } \\
\text { Commercialization }\end{array}$ & $\begin{array}{c}\text { Executive } \\
\text { Information on } \\
\text { Commercialization }\end{array}$ & - \\
\hline
\end{tabular}

In the following phase, the information analyst should establish a relation between the CISs and the processes. Having obtained the relations between the strategic criteria, processes and CISs, the evaluation of the processes in the light of the strategic criteria for the CISs will be transferred to ISM. Since what is desired is the evaluation not only of the CISs, but of the ISMs in the light of the strategic criteria, and as an ISM is a combination of CIS and IFA, one can obtain from the information analyst the matrix which represents the degree of participation of the IFAs in each CIS. 
The matrix with the evaluation of the ISMs for each strategic criterion is obtained by means of the relation $m_{i j}^{c}=t a_{i j} \cdot g_{j}^{c}$, in which $g_{j}^{c}$ corresponds to the columns of Table 2. The ISMs are evaluated for each strategic criterion. In an analogous way to what was done for the strategic criteria, the evaluation of the ISMs for the criteria of processes should be obtained.

Based on the relation $\left\|g_{j}^{c}\right\|=\left\|r a_{i j}\right\|\left\|p_{j}^{c}\right\|$ and now applying $m_{i j}^{c}=t a_{i j} \cdot g_{j}^{c}$ to the criteria of processes, the evaluation of the ISMs for the criteria of processes is obtained next. Thereafter, the evaluation of the ISMs for the technical criteria should be obtained from the information analyst. To do so, an analysis of the IFAs needs to be made in the light of the technical criteria, which corresponds to a) the technological Opportunity; and b) the relative cost of the Technology. The evaluation of the IFAs for the above criteria is then obtained from the information analyst.

In order to have relative weighting among the strategic, process and technical criteria, what is obtained from the decision-maker is a relative weighting between the group of strategic criteria and the other criteria, which in this case is 0.6 for the strategic criteria and 0.4 for the other criteria. Table 5 summarizes the final relative weighting of the criteria adopted.

Table 5 - Weight of the criteria adopted.

\begin{tabular}{|c|c|c|}
\hline Group of criteria & Criterion & Final weight \\
\hline \multirow{3}{*}{ Strategic } & New technologies (C1) & 0.08 \\
\cline { 2 - 3 } & Opportunity for new business (C2) & 0.24 \\
\cline { 2 - 3 } & Quality of service (C3) & 0.21 \\
\hline \multirow{2}{*}{ Technical } & Technological opportunity (C4) & 0.07 \\
\cline { 2 - 3 } & Relative cost of the technology (C5) & 0.07 \\
\hline \multirow{2}{*}{ Process } & The user's commitment (C6) & 0.21 \\
\cline { 2 - 3 } & Importance of automation (C7) & 0.12 \\
\hline
\end{tabular}

Having obtained the evaluations of the ISMs for all the criteria and the weighting of these, then a multicriteria method can be used to make the proper evaluation of IS/IT projects. The results shown in Table 6 can be input into a multicriteria method. Also, the cost for each project is given in Table 6. It has been considered a budget of $\$ 6,596,700$.

Now the application of the PROMETHEE V method with the $c$-optimum concept may be conducted.

\section{2 $c$-optimum PROMETHEE V application}

PROMETHEE presents six different forms of how the decision-maker may represent his/her preferences, not necessarily using the same form for all the criteria. For this application it was the first form related to the true criteria (Brans \& Vincke, 1985) that was considered.

Applying PROMETHEE V and the $c$-optimum portfolio concept, by using the proposed procedure for comparing portfolios, two portfolios are found to be feasible in addition to the classical solution for PROMETHEE V. Table 7 shows the three $c$-optimum portfolios that can be alternative solutions for this problem. 
Table 6 - Evaluation ISMs by each criterion $(\times 100)$ and cost of projects implementation $(\$ 1.00)$.

\begin{tabular}{|c|c|c|c|c|c|c|c|c|}
\hline ISM & $\mathrm{C} 1$ & $\mathrm{C} 2$ & $\mathrm{C} 3$ & $\mathrm{C} 4$ & $\mathrm{C} 5$ & $\mathrm{C} 6$ & $\mathrm{C} 7$ & Cost \\
\hline 1 & 0.75 & 0.4 & 0.8 & 0.8 & 0.45 & 1.5 & 4 & 311,600 \\
\hline 2 & 0.75 & 0.4 & 0.8 & 0.8 & 0.45 & 1 & 1 & 269,000 \\
\hline 3 & 3 & 1.6 & 3.2 & 3.2 & 1.8 & 7.5 & 3 & 738,200 \\
\hline 4 & 3 & 1.6 & 3.2 & 3.2 & 1.8 & 15 & 5 & 713,700 \\
\hline 5 & 4 & 2 & 4 & 4 & 4 & 1.5 & 4 & 364,400 \\
\hline 6 & 3.2 & 1.6 & 3.2 & 3.2 & 3.2 & 2 & 2 & 573,600 \\
\hline 7 & 0.8 & 0.4 & 0.8 & 0.8 & 0.8 & 2.5 & 1 & 342,500 \\
\hline 8 & 1.2 & 1.13 & 2.25 & 2.25 & 2.18 & 1.5 & 4 & 559,500 \\
\hline 9 & 1.6 & 1.5 & 3 & 3 & 2.9 & 2 & 2 & 236,400 \\
\hline 10 & 0.8 & 0.75 & 1.5 & 1.5 & 1.45 & 5 & 2 & 459,300 \\
\hline 11 & 0.4 & 0.38 & 0.75 & 0.75 & 0.73 & 9 & 3 & 768,300 \\
\hline 12 & 13.65 & 14.48 & 7.95 & 10.95 & 10.88 & 0.75 & 2 & 660,000 \\
\hline 13 & 22.75 & 24.13 & 13.25 & 18.25 & 18.13 & 1 & 1 & 498,400 \\
\hline 14 & 9.1 & 9.65 & 5.3 & 7.3 & 7.25 & 2.5 & 1 & 198,800 \\
\hline 15 & 6.08 & 7.31 & 6.98 & 8.78 & 8.89 & 7.5 & 20 & 709,000 \\
\hline 16 & 1.35 & 1.63 & 1.55 & 1.95 & 1.98 & 3 & 3 & 431,800 \\
\hline 17 & 0.68 & 0.81 & 0.78 & 0.98 & 0.99 & 2.5 & 1 & 477,300 \\
\hline 18 & 5.4 & 6.5 & 6.2 & 7.8 & 7.9 & 11.51 & 17.26 & 734,300 \\
\hline 19 & 1.7 & 2.2 & 2 & 1.3 & 2 & 0.75 & 2 & 238,600 \\
\hline 20 & 4.25 & 5.5 & 5 & 3.25 & 5 & 2.5 & 1 & 442,000 \\
\hline 21 & 2.55 & 3.3 & 3 & 1.95 & 3 & 3 & 1 & 808,800 \\
\hline 22 & 5.2 & 5.1 & 9.8 & 5.6 & 5.7 & 1.5 & 4 & 160,100 \\
\hline 23 & 3.9 & 3.83 & 7.35 & 4.2 & 4.28 & 1 & 1 & 817,100 \\
\hline 24 & 2.6 & 2.55 & 4.9 & 2.8 & 2.85 & 2.5 & 1 & 834,300 \\
\hline 25 & 1.3 & 1.28 & 2.45 & 1.4 & 1.43 & 3 & 1 & 846,100 \\
\hline & & & & & & & & \\
\hline 19 & & & & & & \\
\hline
\end{tabular}

The second column of Table 7 shows the result of the first step of the proposed procedure (Section 3.3) for comparing portfolios. That is, the PROMETHEE V classical solution given by (6), in which, $c=p=14$. The third and fourth columns correspond to results of the second step. That is, the $c$-optimal portfolios by solving the model in (8) are given for $c=15$ and $c=16$.

Results of Step 3, by applying (9) are shown in Table 8 .

Then, after applying Step 4, the following result is found: $C(c 15, p)=0.67$. By applying Step 5, a recommendation is obtained for the $c$-optimal portfolio with $c=15$. The results of 
Table 7 - Portfolios selected.

\begin{tabular}{|c|c|c|c|}
\hline ISM & $\begin{array}{l}\text { PROMETHEE V; } \\
\qquad c=p=14\end{array}$ & $\begin{array}{c}c \text {-optimum; } \\
\quad c=15\end{array}$ & $\begin{array}{c}c \text {-optimum; } \\
\quad c=16\end{array}$ \\
\hline 1 & 0 & 0 & 1 \\
\hline 2 & 0 & 1 & 1 \\
\hline 3 & 1 & 0 & 0 \\
\hline 4 & 1 & 1 & 0 \\
\hline 5 & 1 & 1 & 1 \\
\hline 6 & 0 & 1 & 0 \\
\hline 7 & 0 & 1 & 1 \\
\hline 8 & 0 & 0 & 0 \\
\hline 9 & 1 & 1 & 1 \\
\hline 10 & 1 & 0 & 1 \\
\hline 11 & 0 & 0 & 0 \\
\hline 12 & 1 & 1 & 1 \\
\hline 13 & 1 & 1 & 1 \\
\hline 14 & 1 & 1 & 1 \\
\hline 15 & 1 & 1 & 1 \\
\hline 16 & 1 & 1 & 1 \\
\hline 17 & 0 & 0 & 1 \\
\hline 18 & 1 & 1 & 1 \\
\hline 19 & 1 & 1 & 1 \\
\hline 20 & 1 & 1 & 1 \\
\hline 21 & 0 & 0 & 0 \\
\hline 22 & 1 & 1 & 1 \\
\hline 23 & 0 & 0 & 0 \\
\hline 24 & 0 & 0 & 0 \\
\hline 25 & 0 & 0 & 0 \\
\hline
\end{tabular}

Table 8 - Portfolios performance per criterion.

\begin{tabular}{|c|c|c|c|}
\hline Criteria & $\begin{array}{c}\text { PROMETHEE V; } \\
c=p=14\end{array}$ & $\begin{array}{c}c \text {-optimum; } \\
c=15\end{array}$ & $\begin{array}{c}c \text {-optimum; } \\
c=16\end{array}$ \\
\hline C1 & 0,819 & 0,828 & 0,789 \\
\hline C2 & 0,839 & 0,840 & 0,828 \\
\hline C3 & 0,729 & 0,730 & 0,697 \\
\hline C4 & 0,801 & 0,802 & 0,771 \\
\hline C5 & 0,797 & 0,809 & 0,788 \\
\hline C6 & 0,620 & 0,550 & 0,470 \\
\hline C7 & 0,673 & 0,663 & 0,663 \\
\hline
\end{tabular}


Table 3 are also shown in Figure 1, which allows a better visualization of the performance of portfolio $\mathrm{C} 15$ (with $c=15$ ). It can be seen that portfolio $\mathrm{C} 15$ is the best for five criteria $(\mathrm{C} 1, \mathrm{C} 2$, $\mathrm{C} 3, \mathrm{C} 4$ and $\mathrm{C} 5$ ) and the worst for only one criterion (C7). The $p$-optimal portfolio is the best for two criteria $(\mathrm{C} 6, \mathrm{C} 7)$. The portfolio $\mathrm{C} 16$ (with $c=16$ ) is the worst for six criteria.

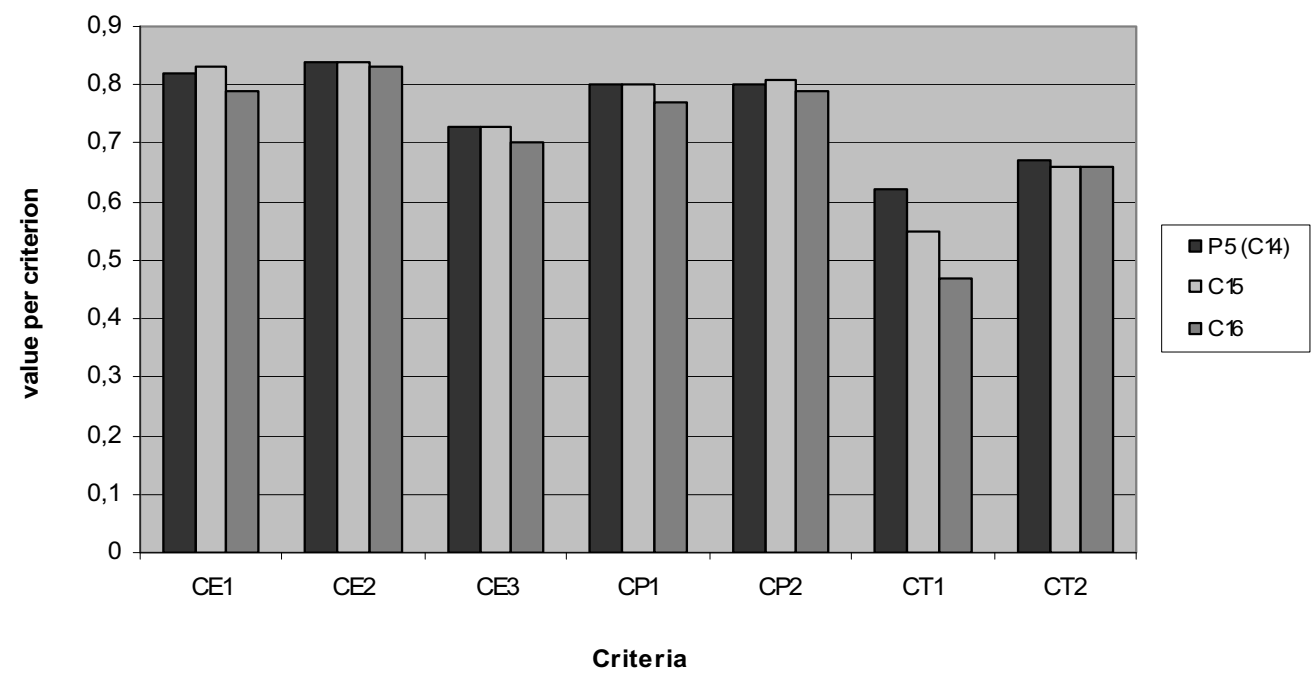

Figure 1 - Portfolios value per criterion.

Hence, for this particular problem only three possible portfolios are feasible and deserve further evaluation. This evaluation shows that one of the portfolios has is the best for five criteria and has the best overall performance comparing these three portfolios, with the procedure proposed, which can capture this issue, once it indicates a performance of $C(c 15, p)=0.67$, in a scale of 0 to 1 .

Next section presents a discussion on the overall procedure proposed and also on this numerical application.

\section{DISCUSSION OF RESULTS}

As mentioned before there are a great amount of work related to multicriteria portfolio problems, although most of them are related to compensatory rationality, main of them related to additive models.

With regard to non-compensatory rationality the main method considered is the PROMETHEE V. It has been discussed a scaling problem related to this method, which requires the use of the $c$-optimal concept, although it has been pointed out by Almeida \& Vetschera (2012) that a procedure in order to implement this concept still needs further issue to be developed.

A comparison between two multicriteria methods is based on an analysis of the axiomatic structure of these methods. Therefore, with regard to the PROMETHEE V method, applied in this paper and the additive model, which is often applied in portfolio problems the main issue to be 
considered is related to the kind rationality considered in both situations. The former is based on a non-compensatory rationality and the latter is based on a compensatory rationality. In this paper it has been assumed that the DM has a non-compensatory rationality. Another comparison issue between these two multicriteria approaches is that the additive model has stronger assumptions than PROMETHEE methods, which should require additional evaluation and checking with the DM, before implementation. It is worthy to recall that additive models require mutual preferential independence among all criteria. This should be carefully evaluated, since the additive aggregation model may incur in errors if this independence condition does not hold. Generally, the studies found in literature related to multicriteria additive models in portfolio do not mention this issue, which should be an important concern.

Additionally, with regard to additive multicriteria portfolio it should be observed the baseline problem pointed out by Clemen \& Smith (2007). If this issue is not observed inadequate solutions may be obtained in the standard procedure. On the other hand the PROMETHEE V method does not have this problem indicated by Clemen \& Smith (2007), although the scaling corrections due to negative scores, require the implementation of the procedure proposed in this paper, based on Almeida \& Vetschera (2012) considerations.

From those results in the numerical application, two topics deserve discussion. The first is on the application of a new procedure for PROMETHEE V, considering the $c$-optimal concept. The second is the use of an integrated process view of the organization in order to evaluate IS projects.

With regard to the use of PROMETHEE V, the results show that the classical result of a $p$-optimal portfolio is not the most appropriate recommendation for the $\mathrm{DM}$, in this particular application. Furthermore, the use of the $c$-optimal portfolio concept shows another portfolio that may be better than the $p$-optimal portfolio. Finally our proposed procedure (Section 3.3) makes a comparison among those three selected portfolios and indicates which the best is.

In this case, three portfolios are considered. The $c=p=14, c=15$ and $c=16$. We should note that the $c=p=14$ is the recommended by the classical PROMETHEE V approach, which we have called $p$-optimal portfolio, since $c=p$ ( $p$ is the size of the portfolio, with the classical PROMETHEE V approach).

From Figure 1, the DM can see which outcomes for each portfolio can be obtained. Following the rationality for outranking methods, the intensity for each portfolio is not the main issue here. In non-compensatory rationality the main issues may be:

a) for which criteria is one portfolio better than others?

b) how can a $c$-optimal portfolio be best compared with the $p$-optimal portfolio?

The first issue is illustrated in Table 8, showing the advantages of portfolio C15, which is better than the $p$-optimal portfolio for criteria $\mathrm{C} 1, \mathrm{C} 2, \mathrm{C} 3, \mathrm{C} 4$ and $\mathrm{C} 5$. The chart in Figure 1 illustrates the outcomes that were found for each portfolio by enabling a visual comparison between them to be made. In this case, it can be seen that the advantage of $\mathrm{C} 15$ over the $p$-optimal portfolio is apparent for criteria $\mathrm{C} 1$ and $\mathrm{C} 5$. However, for criteria $\mathrm{C} 2, \mathrm{C} 3$ and $\mathrm{C} 4$ it can be observed that this advantage of portfolio $\mathrm{C} 15$ over the $p$-optimal portfolio is not notable. 
The second question is analyzed by the proposed procedure given in the Section 3.3. Then, each $c$-optimal portfolio is compared with the $p$-optimal portfolio, in order to find the best one. Based on that, portfolio $\mathrm{C} 15$ is the best for the criteria that sum up to 0.67 of weights, when compared to the $p$-optimal portfolio. That is, portfolio $\mathrm{C} 15$ is the best for the criteria that sum up to 0.67 of weights, when compared to the $p$-optimal portfolio. On the other hand, the $p$-optimal portfolio has advantage for criteria which sum up only to 0.33 of weights. This $p$-optimal portfolio would be chosen applying the classical approach for PROMETHEE V.

This means that, for a non-compensatory logic, portfolio $\mathrm{C} 15$ may be considered better than the $p$-optimal portfolio. This procedure is compatible with the outranking methods concept, since it shows a degree of concordance related to the outranking relation between $\mathrm{C} 15$ and the $p$-optimal portfolio. That is, the evaluation procedure uses the concordance concept of outranking relation between two elements.

Summarizing, the procedure proposed in Section 3.3, apply an outranking and non-compensatory evaluation in order to make comparison among the feasible $c$-optimal portfolios found. In this case we have found only three portfolios to be compared. This shown that for this kind of problem this is not a cumbersome procedure.

Contrary to a first feeling one could take on this regard, making use of the proposed procedure and the $c$-optimal portfolio concept is not too cumbersome. As previously stated, one does not need to consider $c$-optimum portfolios with $c<p$. That is, it has been already proved that all class of portfolios where $c<p$ can not have a better performance and should not be considered (Almeida \& Vetschera, 2012). This is one of the reasons why the use of this concept of $c$-optimal portfolio is not cumbersome. The second reason is related to the fact that many $c$-optimal portfolios with $c>p$ are not feasible, since the costs for adding new projects become costly. That is, this is limited by the main constraint in this kind of portfolio analyzed. Actually, in practice, a small number of portfolios have to be compared with the procedure proposed in this paper, considering the kind of problem analyzed in the organizational context of IS project selection. Therefore, for the particular class o problems discussed and demonstrated in this paper the use of the concept of $c$-optimal portfolio is not at all too cumbersome to be applied.

Therefore, the numerical result given above illustrates a situation in which the classical PROMETHEE V may not be able to give the best portfolio result. However, the use of the $c$-optimal portfolio concept associated with the PROMETHEE V method may present a satisfactory result, still in accordance with the DM's non-compensatory rationality.

With regard to the second topic, the use of an integrated organizational process view in order to evaluate IS projects, some considerations may be given related to the results.

One of the positive aspects of the model proposed in this paper is to require the decision-maker to give information that he/she is able to supply, such as: the relative importance among the strategic criteria, the relationship between the strategic criteria and macro-processes, and the relative importance among the process criteria. The other information used in the model is obtained automatically through transfer by means of the operations with matrices and also from an 
information analyst, such as: the relationship of the CIS with the macro-processes, the evaluation of IFAs in relation to the technical criteria and the relationships between IFA and CIS.

Based on above observations, some Managerial Implications may be pointed out:

- The selection model proposed deals with aspects present in the problem of selecting ISs, such as the strategic vision of the organization, the vision of the processes and the technological vision.

- The multicriteria method used in the model permits aspects to be incorporated which involve the situation of the organization, internally with regard to its information needs; and externally, with respect to its positioning on the market, by means of choosing the criteria, defining the relative importance between them, and the thresholds of indifference and preference.

- The search for integration between the business vision and the IS portfolio is consolidated with the use of strategic criteria in selecting the ISs, such criteria being defined, based on the organization's strategic vision and on its critical factors for success.

- This study fills a gap in the literature of IS, which is how to tackle the problem of IS selection as a multicriteria decision problem in an IS planning context.

- The proposed model, although it presents a structure with matrices, requests information from the decision-maker that he is able to supply. The model could be easily supported by a Decision Support System, thus making it an easier tool to use and very useful for business managers and Information Systems managers, to help them in their decision taking with regard to allocating resources for IS projects.

An important issue to be considered in future studies is related to the possibility of using a visual procedure to allow the DM making the final comparison and evaluation of portfolios, since only a few feasible $c$-optimal portfolios is likely to be found in the procedure proposed in Section 3.3. Kiesling et al. (2011) present an interesting study related to visualization methods for multicriteria portfolio selection that may be useful for an adaptation in a future work on the kind of problem approached here.

\section{CONCLUSION}

In the model presented, the selection of ISs was conducted in a broad context of IS Planning, and thus integrated with a Planning methodology, this being developed as a stage of this methodology. The IS Planning methodology tackles the problem of integrating the IS plan with the organization's business plan as a form of aggregating value to the decision of investing in ISs. This ensures the pursuit of the organization's objectives and furthermore permits a complete study of the organizational objectives. For the Planning context, the proposal is to include more than one stage in the methodology in order to identify the most important strategic information needs which the original methodology does not undertake. 
To tackle the selection of ISs, a model based on multicriteria decision-making is used, integrated with the referential methodology for IS Planning. In order to make such integration possible, an analytical structure is applied, which permits the evaluations of ISs to be obtained so as to incorporate the multicriteria method PROMETHEE V. This method is appropriate for selecting a portfolio of IS projects instead of selecting IS projects only.

Therefore, the PROMETHEE V method can be applied. In this case some aspects need to be considered. The first aspect to be considered is the non-compensatory rationality of the decisionmaker. In other words, when evaluating the alternatives, the decision-maker expresses a preference for alternatives that present a satisfactory performance in a criterion, instead of compensating for the poor performance in one criterion by a good performance in another criterion. Another two important aspects are that the decision-maker needs to understand the meaning of the relative importance among the criteria and also the meaning of the several possibilities of function.

Also, considering recent results related to the use of PROMETHEE V, the $c$-optimal portfolio concept is applied in order to select the best portfolio in accordance with the DM's preferences. A procedure for analyzing and compare the results of classical PROMETHEE V and $c$-optimal portfolio in PROMETHEE V is proposed and used as per the illustration given in the numerical application. Furthermore, it has been considered the possibility of future studies related to the use of visual procedures to allow the DM making the final comparison and evaluation of portfolios, such as those proposed by Kiesling et al. (2011).

\section{ACKNOWLEDGMENTS}

This research has been partially supported by CNPq (Brazilian Research Council).

\section{REFERENCES}

[1] Almeida AT de, Bohoris GA \& Steinberg H. 1992. Managenment information and decision support system of a telecomunication network. Journal of Decision Systems, 1(2-3): 213-241.

[2] Almeida AT DE. 1999. Um Modelo de Decisão Para Priorização No Planejamento de Sistemas de Informação. Produção, 8(2): 169-185.

[3] Almeida AT de \& Costa APCS. 2002. Modelo de Decisão Multicritério para Priorização de Sistemas de Informação Baseado no Método PROMETHEE. Gestão e Produção, 2(9): 201-214.

[4] Almeida AT de \& Vetschera R. 2012. A note on scale transformations in the PROMETHEE V method. European Journal of Operational Research, 219: 198-200.

[5] Angelou NG \& Economides AA. 2008. A Decision Analysis Framework for Prioritizing a Portfolio of ICT Infrastructure Projects. IEEE Transactions on Engineering Management, 55: 479495.

[6] Argyris N, Figueira JR \& Morton A. 2011. Identifying preferred solutions to Multi-Objective Binary Optimisation problems, with an application to the Multi-Objective Knapsack Problem. $J$. Global. Optim., 49: 213-235. 
[7] Behzadian M, Kazemzadeh R, Albadvi A \& Aghdasi M. 2010. PROMethee: A comprehensive literature review on methodologies and applications. European Journal of Operational Research, 200: 198-215.

[8] BERgERON F, RAYMOND L \& RiVARD S. 2004. Ideal patterns of strategic alignment and business performance. Information \& Management, 41: 1003-1020.

[9] BernRoider EWN \& STIX TV. 2006. Profile distance method - a multi-attribute decision making approach for information system investments. Decision Support Systems, 42: 988-998.

[10] BRANS JP \& MARESCHAL B. 1992. PROMETHEE V: MCDM problems with segmentation constraints. INFOR, 30(2): 85-96.

[11] BRANS JP \& VINCKE P. 1985. A preference ranking organization method. Management Science, 31(6): 647-656.

[12] Brans J, Mareschal B \& Vincke P. 1984. PROMETHEE: A new family of outranking methods in multicriteria analysis. In: BRANS J. (ed.), Operational Research '84, pp. 477-490. North Holland, Amsterdam.

[13] Chen CT \& Cheng H-L. 2009. A comprehensive model for selecting information system project under fuzzy environment. International Journal of Project Management, 27: 389-399.

[14] Clemen RT \& Smith JE. 2009. On the Choice of Baselines in Multiattribute Portfolio Analysis: A Cautionary Note. Decision Analysis, 6: 256-262.

[15] Doherty NF, Marples CG \& Suhaimi A. 1999. The relative success of alternative approaches to strategic information system planning: an empirical analysis. The Journal of Strategic Information Systems, 8: 263-283.

[16] HaCKNEY R \& LiTTLE S. 1999. Opportunistic strategy formulation for IS/IT planning. European Journal of Information Systems, 8: 119-126.

[17] Henderson JC \& Venkatraman N. 1999. Strategic alignment: leveraging information technology for transforming organizations. IBM Systems Journal, 38: 472-484.

[18] Jiang JJ \& Klein G. 1999. Project selection criteria by strategic orientation. Information \& Management, 36: 63-75.

[19] KeARns GS \& LEDERER AL. 2004 The effect of strategic alignment on the use of IS-based resources for competitive advantage. Journal of Strategic Information Systems, 9: 265-293.

[20] Kiesling E, Gettinger J, Stummer C \& Vetschera R. 2011. An Experimental Comparison of Two Interactive Visualization Methods for Multicriteria Portfolio Selection. In: SALO A, KEISLER J \& Morton A. Portfolio Decision Analysis - Improved Methods for Resource Allocation, Springer.

[21] Klapka J \& Pinos P. 2002. Decision support system for multicriterial R\&D and information systems projects selection. European Journal of Operational Research, 140: 434-446.

[22] Kleinmuntz DN. 2007. Resource allocation decisions. In: Edwards W, Miles RF \& voN Winterfeldt D. (eds), Advances in decision analysis. CUP, Cambridge.

[23] LEE JW \& KIM SH. 2000. Using analytic network process and goal programming for interdependent information system project selection. Computers \& Operations Research, 27: 367-382.

[24] Liesiö J, Mild P \& SAlo A. 2008 Robust portfolio modeling with incomplete cost information and project interdependencies. European Journal of Operational Research, 190(3): 679-695. 
[25] Mavrotas G, Diakoulaki D \& Caloghirou Y. 2006. Project prioritization under policy restrictions: A combination of MCDA with 0-1 programming. European Journal of Operational Research, 171(1): 296-308.

[26] Mehrez A, Howard GS, Lugassi Y \& Shoval P. 1993. Information System Planning and Selection: A Multiattribute Theoretic Approach. The Computer Journal, 36: 525-541.

[27] Mild P \& SAlo A. 2009. Combining a multiattribute value function with an optimization model: an application to dynamic resource allocation for infrastructure maintenance. Decis. Anal., 6(3): $139-152$.

[28] Milis K \& Mercken R. 2004. The Use of the Balanced scorecard for the evaluation of Information and Communication Technology projects. International Journal of Project Management, 22: 87-97.

[29] Min SK, SUH EH \& KIM SH. 1999. An integrated approach toward strategic information systems planning. The Journal of Strategic Information Systems, 8: 373-394.

[30] Pollalis YA. 2003. Patterns of co-alignment in information-intensive organizations: business performance through integration strategies. International Journal of Information Management, 23: 469-492.

[31] Salo A, Keisler J \& Morton A. 2011. Portfolio Decision Analysis - Improved Methods for Resource Allocation, Springer.

[32] Schniederjans MJ \& Santhanam R. 1993 A multi-objective constrained resource information system project selection method. European Journal of Operational Research, 70: 244-253.

[33] Sprague JR RH \& Watson HJ. 1989. Decision Support Systems - Putting Theory into Practice, Prentice-Hall, Inc.

[34] TEO TSH \& ANG JSK. 1999. Critical success factors in the alignment of IS plans with business plans. International Journal of Information Management, 19: 173-185.

[35] TEO TSH \& KING WR. 1996. Assessing the impact of integrating business planning and IS planning. Information \& Management, 30: 309-321.

[36] TeO TSH \& King WR. 1997. Integration between Business Planning and Information Systems Planning: An Evolutionary-Contingency Perspective. Journal of Management Information Systems, 14: $185-214$.

[37] Vetschera R \& De Almeida AT. 2012. A PROMETHEE-based approach to portfolio selection problems. Computers and Operations Research, 39: 1010-1020.

[38] Zopounidis C. 1999. Multicriteria decision aid in financial management. European Journal of Operational Research, 119: 404-415. 